\title{
The fertility desire and its decision-making logic of senior intellectual females --- A case study of female teachers in colleges and universities Kejun Wang
}

College of Social Sciences, Chinese University of Hong Kong, Hong Kong Special Administrative Region, China

Mailing address: Sha Tin, New Territories, Hong Kong Special Administrative Region, 999077, China

Key words: senior intellectual females; fertility desire; decision-making logic

\begin{abstract}
As a country with a large population, the research on the willingness of fertility has always been an important issue. Especially in October 2015, our national government have decided to fully implement the policy that one couple can have two children, which makes issue of fertility desire has become a hot issue again.

This paper, through the qualitative research method and under the guidance of practice theory, aims to study the fertility desire and its decision-making logic of senior intellectual females. The purpose of this study is not only to understand the fertility desire of senior intellectual females, but also to analyze the factors that influence their willingness to fertilize, so as to summarize and conclude the decision-making logic of fertility desire of them, thereby to understand how the object of the study is to make fertility decision-making, and ultimately a fertility decision-making logic system showed.

The innovation of this article is mainly on the study of the fertility willingness of a certain group of women - seinor intellectual female in the hope that people will think deeply about the logic of fertility decision-making through the study of this special groups.
\end{abstract}

\section{Origin of the problem}

In recent years, our country have adjusted the childbearing policy for several times. Until October 2015, our national government have decided to fully implement the policy that one couple can have two children. Fertility desire is not only an important factor to affact the fertility level, but also an important indicator to predict the future trend of population development.

This study focuses on the fertility desire of the senior intellectual women and their decision-making logic. In the perspective of social practice theory, this study aims to study how and what kind of fertility desires are come into being under what decision-making logic for senior intellectual females, a group with stable jobs, well paid and high social status etc. On the one hand, this study can explain the fertility desire and its decision-making logic from the special theoretical perspective, and supplement and enrich the theoretical perspective of the current study of fertility desire. On the other hand, it is helpful to provide the methodological reference and research path for the study of the fertility desire of various specific groups.

\section{Overview of fertility desire of senior intellectual females}

The involved 15 subjects of this study are from two universities in Zhengzhou City, Henan Province, among which 12 are married, 3 unmarried; 11 have been born with one child, including one person with twins, and another 4 unbearing; 2 have bachelor degree, 12 master degree, and 1 $\mathrm{PhD}$ degree; 5 are age less than 30 years old, 6 age between 30-35 years old, 3 age between 36-40 years old, and 1 age above 40 years old. Their fertility desire can be explained from the following two aspects:

1) Narrow sense of fertility desire

In a narrow sense, that is the number of childbearing willingness, the fertility desire of senior intellectual female are less than or equal to 2 children. 


\section{2) Broad sense of fertility desire}

The broad sense of fertility desire includes the desired number of children, gender, timing of birth and spacing of birth, etc. The number of fertility desire has been mentioned. As for the birth time, 6 who have clearly expressed the will of a second child all make it clear that they will give birth to a second child before 37 years old. While most people hope that there is a 3-5 years birth spacing of the two children.

\section{Analysis of factors influencing the decision making of fertility desire}

\subsection{Field Analysis}

\subsubsection{Family Field}

As a basic unit of society, the family is "the cell of society". Family field also have great impact on individuals. What is the position of a person in the family structure, as well as what kind of relationship between the person and other family members, also will have a significant impact on her fertility intentions.

The mother-in-law and daughter-in-law conflict is also a common topic when it comes to family issues. Since ancient time, it seems that mother-in-law and daughter-in-law will oppose naturally. However, in the survey, the author found that senior intellectual women could better deal with the relationship with their mother-in-law. Although people cannot rule out the existence of the conflict, few people actually have a head-on confrontation with their mother-in-law.

The "men outside the home, women inside" point of view is a kind of Chinese traditional family division of labor mode. Along with the progress of the society, this kind of situation has changed, but the traditional family division of labor mode of inertia still exists. To a large extent, women assume most of the family responsibilities while taking on almost the same responsibilities as men, which leads to an increase of the family status of women, but they become more tired at the same time.

In general, the family field is one of the most important fields of personal life, and it also plays an important role in the decision-making of fertility will of senior intellectual women.

\subsubsection{Professional field}

Many people believe that the university teachers should be more relax with relatively small pressure, summer and winter vocations and abundant time, but in fact it is not. it is found that many of the respondents did pay more efforts in taking care of their children and their husbands due to their stable and fixed work and holiday time. Of course, as a special professional field, colleges and universities are also virtually shaping the fertility of its staff will.

\subsubsection{Conflict between career development and birth decision making}

A very realistic problem for college teachers and workers is conferring of academic titles. The pressure of job promotion does exist. Not only that, it will also brings influence to their work because of taking care of their children in the daily teaching work. Many female teachers said that they always spent the times after work to accompany their child. After the child fell asleep, she had time to prepare lessons or do some work, which was basically after 9:30 pm.

\subsubsection{Convergence of fertility desire under occupational fields}

In such a specific occupation field in universities and even in any specific field, the concept of each person will have certain similar characteristics due to the special influence of the field. In the daily work, people and their colleagues have more interactions. Everyone has their own good relationship colleagues, and it is inevitable to talk about the topic of child-rearing in the exchange.

3.1.3 The Influence of peer group field

Peer groups tend to be more likely to have an impact on a person than their elders or predecessors. Because experience of the peer group will make individuals feel more specific and more empathetic. This is also the root cause of the impact of peer groups on the decision-making of fertility will. In their peers, how most people do, or what some special people will do, will have produce a significant stimulus to the individual and thereby influencing their making decisions. 


\subsubsection{Social environment field}

Social environment is the sum of social material and spiritual conditions in the range of human existence and activities. In a broad sense, it includes the whole social economic and cultural system, while the narrow sense refers only to the direct environment of human life. The social environment field seems to be more difficult to perceive, which makes it hard for people to realize that their choices are influenced by the social environment. But this kind of power can not be ignored. The word "trend" can best describe the irresistible force created by the social environment, which makes people make a specific choice unknowingly with the power. Social environment plays an important role in the topic of fertility desire decision.

In addition, with the popularity of the Internet, the virtual social environment has a partial impact on the decision of the people's fertility desire.

However, policy factors, as an important aspect of the social environment, have a relatively weak impact on women's fertility desire.

\subsection{Capital analysis}

\subsubsection{Economic Capital}

Economic capital, as mentioned in the theory of practice, is made up of different factors of production, economic property, various income and economic benefits. The economic capital of individuals and families determines the ability to bear, raise a child, or more children. Of the 15 subjects, 8 explicitly defined "economic conditions" as the most important factors influencing their reproductive decisions. There is not enough money to raise a child, which is the most realistic problem. Another aspect that can not be ignored, is the housing. Just married young people often face with the pressure of mortgage, which will bring a greater economic burden to the family.

\subsubsection{Cultural capital}

The cultural capital in the theory of social practice refers to the cultural objects which are transmitted through various kinds of educational activities. The cultural capital here not only refers to the how high a person's education, how much knowledge, etc., but also the cultural concept, cultural cultivation and cultural knowledge stored in individual concept through the individual education and learning, as well as the influence of the cultural environment. This is the so called cultural capital. According to the Maslow's hierarchy of needs, high-level living needs are in fact based on cultural needs. However, senior intellectual females, as a group with a high cultural basis, naturally have a higher level of life needs for themselves and their offspring: 1) Cultural capital makes senior intellectual women produce high expectations for their offspring; 2) Cultural capital makes the senior intellectual women attach importance to personal space and self-consciousness. And this is why "the higher education, the lower fertility desire" in the society.

\section{Decision - making logic of fertility desire}

After analyzing the above factors, it is possible to summarize the decision-making logic of senior intellectual women when making a child-bearing decision. In this decision logic, the field, habit and capital, respectively, have played a different role, and they work together to form a fertility decision-making logic system.

Capital is the most realistic factor that the individual needs to make in the decision-making of the birth. Is there enough economic capital to raise children? What kind of life they want for themselves and their children for the sake of cultural capital? All these problems must be considered in decision making of birth. After the above analysis we can found that economic capital has a major limiting effect on senior intellectual women. Most people in the group did not have enough economic capital to raise two children in their youth, and they might have missed the age to give birth to a second baby when the economic situation have improved. While cultural capital determines the expectations of living standard of senior intellectual women to themselves and their children. Under the influence of cultural capital, senior intellectual women tend not to reduce such standards and expectations. If they choose to raise a child in meeting their own requirements, it will lead to a low level of personal choice. Therefore, the author believes that cultural capital is the fundamental reason to make a fertility decision for senior intellectual women. Under the joint action of economic 
capital and cultural capital, the individual ultimately determines the decision to fertility. Therefore, capital will plays a decisive role in the decision-making logic of fertility desire.

All in all, in this fertility decision-making logic system, field build the fertility decision making, habits guide the fertility decision making, and capital decide the fertility decision making. Under the action of field, capital and habit, the individual's fertility desire can be produced and changed, which is the interpretation of the decision logic of fertility desire in the sociology of practice.

\section{References}

[1] Bourdieu P, Wacquant LD. An Invitation to Reflexive Sociology[M]. Beijing: Central Compilation \& Translation Press. 1998, 131-157.

[2] Youhua Chen, Guo Miao. Things unexpected but inevitable--Why two child policy encounter cold[J]. Exploration and Free Views. 2015, (2).

[3] Xiaotian Feng. Youth Characteristics and their Fertility Desire-A Survey of 1786 young workers in 12 cities[J]. The Journal of Jiangsu Administration Institute. 2009, (4).

[4] Xiaotian Feng. Bearing the Second Child: the Desire of the Both Only Child Couples and the Analysis of Related Factors[J]. Journal of Social Science. 2010, (5):58-189.

[5] Baochang Gu. On fertility and fertility change: quantity, time and gender[J]. Population Research. 1992, (6).

[6] Baochang Gu. Fertility desire, fertility behavior and fertility level[J]. Population Research. 2011, (2).

[7] Jiawei Hou, Silin Huang et al. The Change of Fertility Desire in China: 1980-2011[J]. Social Science in China. 2015, (1).

[8] Zhenwu Zhai, Xianling Zhang, Yongai Jin. Demographic Consequences of an Immediate Transition to a Universal Two-child Policy[J]. Population research. 2014, (3).

[9] Caldwell JC. The Mechanisms of Demographic Change in Historical perspective[J]. Population Studies. 1981, (2).

[10] Zeng Yi. Options for Fertility Policy Transition in China[J]. Population and Development Review. 2007, (2). 